\title{
Observations on the Action of X-rays on Plant Cells.
}

\author{
BY
}

MAUD WILLIAMS.

\section{INTRODUCTION.}

$\mathrm{T}$ HE present work arose out of experiments upon the changes produced when certain plant cells are immersed for long periods in solutions of electrolytes (1). An empirical formula had been obtained connecting the concentration of a particular salt solution employed and the time of immersion needed to produce a specific change in the cells studied. This change, which is also employed in the present work, was judged to have taken place when a $0 . \mathrm{I}$ per cent. $\mathrm{K}_{2} \mathrm{Cr}_{2} \mathrm{O}_{7}$ solution was able to enter the cells and combine with the tannin contents to yield a precipitate within a time limit of three minutes. The results obtained for series of salts made it seem desirable to study the influence upon living protoplasm of electric charges of one kind only, unhampered by the presence of undissociated molecules or of salt ions.

Treatment with radium seemed a possible way of attaining this object. The ordinary radium bromide preparations give off a particles (positively charged), $\beta$ particles (negatively charged), and X-rays of a very hard type. By using the preparation encased in mica or platinum the a particles are absorbed and the cells can be submitted to the bombardment by the negatively-charged particles, which travel with great velocities, and to the action of the X-rays. It is obvious that the influence of the $\beta$ particles alone can be estimated only when the effects of the X-rays themselves are known.

Although it is not suggested that treatment of plant tissues by either $\mathrm{X}$-rays or by radium is likely to be of practical importance, the investigation of cell behaviour when under these radiations is of great interest from the following points of view:

(a) Possible stimulation.

(b) The coagulation of colloidal matter.

(c) The action of etheric radiations of very short wave-length upon the colouring matters of cells.

The second of these matters is that of chief interest in the work undertaken, but various interesting changes have been observed, and it is proposed to deal with the experiments in a series of short papers.

[Annals of Botany, Vol. XXXVII. No. CXLVI. April, 1923.] 


\section{Section I. Changes produced in Cells of SAXifrage} UMBROSA BY X-RAYS.

I. Historical survey.

2. Nature of the X-rays, factors to be considered.

3. Methods used.

4. The series of changes produced.

5. Summary.

I. The general interest aroused by the discovery of X-rays by Röntgen in 1895 led to the action of these rays on various plant and animal structures being studied at an early date. There are many conflicting statements in the work of the earliest workers, which is only to be expected when one considers the fact that the actual nature of the rays was then unknown and experiments could not be carried out under any standard conditions.

In 1897 observations upon Vallisneria spiralis under the radiation from a 'gas bulb' were published by Lopriore (2). This observer found that treatment for thirty minutes produced an acceleration of circulatory rate, but there was a return to the normal rate when the radiation ceased. Treatment which lasted one hour caused the protoplasm to become yellow, granular, and coarsely vacuolated, while after two hours of radiation, although the cells were still living and the protoplasm circulating, the chlorophyll bodies were becoming colourless. The suggestion of stimulation implied by the acceleration of circulation is supported by the fact that other workers increased the rate of opening of buds by exposing them to $\mathrm{X}$-rays, while it is well known from the medical side that small doses of radiation may accelerate cell division of tumours in animals.

Although Lopriore did not reach the stage in which cells were actually killed while under the radiations, lethal actions were soon discovered during work on animal cells, and Schaudinn.(3) found that treatment for fourteen hours caused amoebae to round themselves off. It was found that many bacteria were peculiarly resistant to these rays, although so powerfully affected by ultra-violet light.

Meanwhile analogous experiments were being made upon cells exposed to radium, and although these will be dealt with in a later paper, attention must here be called to the work of Packard (4), because he suggested that the presence of chlorophyll increased the resistance of the cells, and that the presence of light was a factor of importance in his tests on chlorophyllcontaining cells.

2. It has now been established that X-rays are waves of the same type as light waves but of much shorter wave lengths than those of either visible or ultra-violet light. 
As produced in the original forms of 'gas bulb' these waves are heterogeneous; homogeneity can be obtained by 'filtering' through a suitable thickness of aluminium. On consideration of the more recent work upon light and stimulation it becomes apparent that when one deals with any radiation of the same type as visible light one must be prepared to consider both intensity and 'quality' (i.e. wave length) as important factors in the action upon plant cells.

In any attempt to obtain quantitative results it is necessary to maintain the 'past history' of the material as uniform as possible, to expose cells in the same state of development, to carry on the experiments in darkness, and to use $\mathrm{X}$-rays of homogeneous nature.

3. The material already used in the work on electrolytes referred to earlier proved very suitable for examination under X-rays. When strips were torn from the upper surface of the petiole of Saxifraga umbrosa the cells were in mature condition and very sonstant in shape. They were particularly clear and easy to examine, and rumained in active circulation if kept for as long as forty-eight hours in distilled water (free from copper), and for longer still when kept in tap water. The strips were sufficiently large for division longitudinally for certain tests where accurate control was needed.

For exposure a number of strips was mounted under a cover-slip 1.5 in. by 0.75 in.; if quantitative results were needed this cover-slip was tested for uniform thickness by spherometer measurements. The glass slide was held in a wooden rack with sides to darken it, at a known distance from the focus spot of the X-ray bulb. The bulb itself was contained in the usual way in a lead-lined box with an opening only at the focus region so that scattered rays could not influence the material.

For preliminary work the rays were obtained from the ordinary gas bulb, in which constant output is impossible. This work served to show the changes produced and the order in which they occurred. More accurate work was then undertaken with the Coolidge tube. This modern type of bulb gives heterogeneous rays, and the penetrating power depends upon the difference of potential maintained between the electrodes. The X-rays are produced by the action of electrons given out by a heated spiral of tungsten wire, and the intensity is constant if the temperature of the wire be constant. The heating is carried out by means of an electric current, and the strength of this must be maintained steady in order to give a constant temperature.

Since the penetrating power of the rays depends upon the difference of potential between the electrodes, it can be tested by a 'spark-gap' in circuit with the bulb, and the generator must be adjusted to keep its value constant.

If the radiations are then passed through a centimetre thickness of aluminium one can obtain an output constant in intensity and quality. 
A range of intensities is possible if one places the slide at different distances from the bulb, since the intensities then fall off inversely as the squares of the distances.

4. In following the series of changes strips were removed from the slide after various times of exposure and examined both with the high power and with the paraboloid form of ultra-microscope.

The first change seen was an increase in the rate of circulation, of a type which must be defined clearly. In this material there is no distinct movement of rows of chloroplasts as in some plants, but circulation of the protoplasm is shown by the movement of bright particles, which focusing shows to be near the wall, along lines parallel to the long axes of the cells, and a similar movement along protoplasmic threads leading to the centre of the cell. In all discussion of circulation only bright particles of similar size and appearance, moving along lines parallel to the long walls, are considered.

As exposure proceeded there was an increase in the amount of Brownian movement executed by these particles. Since the temperature was steady and the sizes and optical properties of the particles remained constant, this increase in movement would appear to denote a fall in the viscosity of the medium. As there was a forward motion imposed upon the particles by the movement of the protoplasm it appeared as though relative values of the viscosity at different stages could be obtained by observations on the curves executed by the particles, according to the method used by Svedberg (5). Unfortunately the amplitudes of the vibrations were too small to make such estimations possible.

Longer exposure to the rays caused a diminution of circulatory rate, and finally cessation.

It was hoped to obtain figures of quantitative value by plotting graphs of circulatory rates after various times of exposure, but the movement in the plant cells proved to be influenced by too many factors to make success likely, as the nature of the tests did not allow time to compare the specimen with its own control at each stage.

Measurements were made to find whether the stimulation indicated by increase in circulatory rate was followed by a depression when treatment ceased before there was any outward sign of injury in the cells. For each of these tests strips were divided longitudinally; half was exposed and half kept as a 'control'. Circulatory rate was measured in each at intervalsreadings being taken after ten minutes' exposure to the light of the microscope mirror, and measurements being made as quickly as possible on central cells in the strip.

The table below shows some representative experiments. In no case was the exposure long enough to produce visible injury either after exposure or at the end of twenty-four hours. 
It will be seen that considerable changes took place in the circulatory rates of the controls during the time of the experiments, but in every case the irradiated specimen ultimately showed a depression in rate compared with its control. Precisely analogous results will be shown later in a section dealing with the action of radium on the same material. The effects do not agree with the observation of Lopriore that circulation became normal after cessation of treatment.

Circulatory Rate and Influence of X-Rays.

Coolidge tube. Heating current 3.5 amps.

Cover-slips $0.035 \mathrm{~cm}$. thickness.

Specimens mounted in tap water.

Slide placed at aperture of box enclosing the tube, darkened except for glow of the bulb.

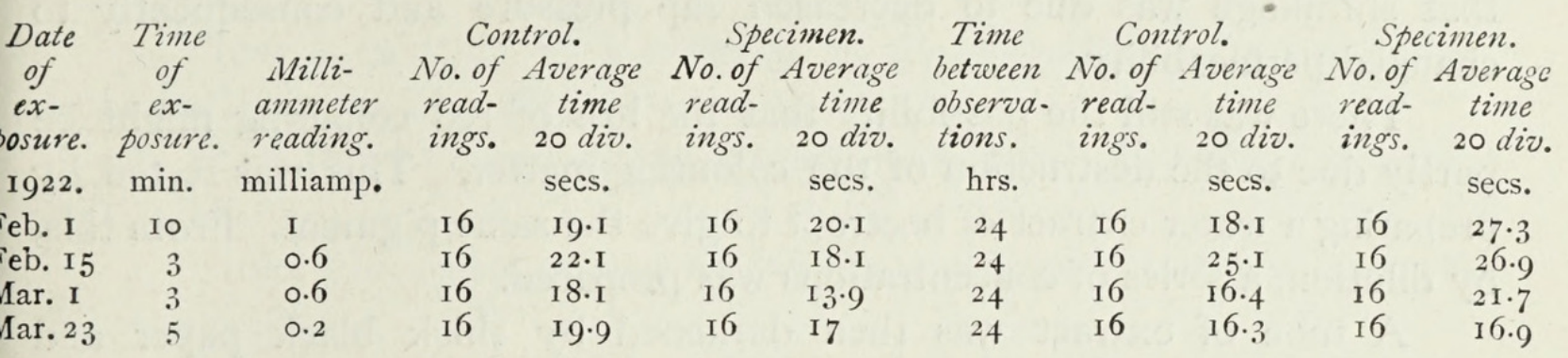

As treatment was extended beyond the time needed to accelerate the circulation other changes occurred. The protoplasm began to leave the cell wall, very gradually at first. In the early stages of this change the protoplasmic surfaces were parts of smooth curves and the clear appearance was retained.

To test whether this shrinkage was of reversible nature treatment was stopped in some cases and camera lucida drawings made of representative cells. The material was then transferred to a fresh supply of tap water and drawings made at intervals with the same focusing arrangements. The area of the protoplasm in these cells was estimated with a planimeter. Not only was there no return to the normal condition, but shrinkage was found to be progressive more than an hour after treatment.

In specimens in which the shrinkage stage had been reached it was noticed that the pink colour possessed by some of the cells was beginning to fade. A possible explanation of both shrinkage and loss of colour was to assume the permeability had been modified and that solutions were escaping from the cell, so lessening the sap pressure.

To test the truth of this assumption experiments were made upon pieces of epidermis torn from the under surface of the leaves of the plants. One strip from each leaf was exposed and the other kept in tap water as a control.

Immediately after exposure to the Coolidge tube the specimens were 
mounted in fresh tap water, and ten stomata, chosen at random, were measured for the stomatal ratio, i.e. the ratio of the width to be the length of the slit.

The control was then dealt with similarly, and both strips kept in fresh supplies of water, in darkness for twenty-four hours. Fresh measurements were then made, care being taken of course to leave each strip over the mirror of the microscope for the same interval before beginning the tests.

Exposure for ten minutes to the Coolidge tube with a reading of two milliamps was found to reduce this ratio very perceptibly, while twenty-four hours after treatment the difference between experimental strip and control was greatly enhanced. On one occasion with more penetrating rays (reading one milliamp) the average for the stomatal ratio was reduced to 0.39 against a value for the control of 0.55 . These results therefore confirmed the view that shrinkage was due to decreased sap pressure and consequently to changed permeability.

There was still the possibility that the loss of red colouring might be partly due to the destruction of the colouring matter. This was tested by preparing a water extract of beetroot to give the same pigment. From this, by dilution, a series of concentrations was prepared.

A tube of extract was then darkened by thick black paper and exposed to a strong dose of rays of duration longer than that found to cause loss of colour in the plant cell. When the liquid was matched against the graded tubes it was found to be unchanged in depth of colour and its absorption spectrum was observed to be identical with that of the original solution. The fact that the chloroplasts were not affected in this material, while those in Vallisneria were found by Lopriore to become yellow, led to tests on chlorophyll extracts similar to those on the red colouring anthocyanin being made.

Exposures up to fifty minutes were made with the Coolidge tube; again no change in intensity was discovered, and the absorption spectrum was identical with that of the control both immediately after exposure and again a week later. Where discoloration has been found to occur in other plants it is possible the cause has been the action of acids released by the changes in permeability and not a direct action of the radiations.

Attention was next paid to the changes in the appearance of the protoplasm on still longer exposures as circulation began to slow down. The shrunken surfaces became more and more irregular, and an increased amount of light was scattered when the cells were viewed with the ultramicroscope. In some cells great vacuolation was found.

Finally a stage was reached when, within three minutes, a solution of $\mathrm{K}_{2} \mathrm{Cr}_{2} \mathrm{O}_{7}$ of $0 \cdot \mathrm{I}$ per cent. could produce a precipitate with the tannin of the cells. The ultra-microscope showed that this precipitate appeared both within the shrunken mass and in the corners of the cells from which the 


$$
\text { X-rays on Plant Cells. }
$$

protoplasm had retreated. The tannin must therefore have been capable of diffusing out as well as the $\mathrm{K}_{2} \mathrm{Cr}_{2} \mathrm{O}_{7}$ diffusing into the protoplasm.

Work which has already been done points to a relationship between intensities used and time of exposure needed to bring the cells to this last stage. It is hoped to deal with this quantitative aspect in a later paper.

\section{SUMmary.}

Strips of tissue from the upper surface of the petiole of Saxifraga umbrosa were subjected to X-rays.

1. Small doses of radiation are said to accelerate circulation, but in this material a depression follows, and there is no return to the normal in twentyfour hours.

2. There is evidence of a lowering of the viscosity of the protoplasm in the early stages of radiation.

3. From the time any change is seen in the protoplasm that change is irreversible.

4. There is no direct influence of the rays upon the anthocyanin or the chlorophyll.

5. The protoplasm allows the diffusion of solutes from the vacuole, and appears to become coagulated.

6. By the time a precipitate can be obtained with the potassium dichromate used as a test for increased permeability all movement of the protoplasm has stopped.

The Sir John Cass Institute, London.

\section{Literature Cited.}

1. Williams, M.: On the Influence of Immersions in certain Electrolytes upon Cells of Saxifraga umbrosa. Ann. Bot., Oct., I 922.

2. Lopriore, G. : Azione dei raggi X sul protoplasma della cellula vegetale vivente. La Nuova Rassegna, 1897 .

3. Schaudinn, F.: Über den Einfluss der Röntgenstrahlen auf Protozoen. Pfligers Archiv, I 899.

4. Packard, C. : Journal of Gen. Physiology, vol. i, No. I, i9i 8.

5. Svedberg, T.: Zeitschrift f. phys. Chem., No. 7I, i910, p. 57 I. 


\section{$2 \mathrm{BHL}$ Biodiversity Heritage Library}

Williams, Maud. 1923. "Observations on the action of x-rays on plant cells." Annals of botany 37, 217-223.

https://doi.org/10.1093/oxfordjournals.aob.a089843.

View This Item Online: https://www.biodiversitylibrary.org/item/270686

DOI: https://doi.org/10.1093/oxfordjournals.aob.a089843

Permalink: https://www.biodiversitylibrary.org/partpdf/319080

\section{Holding Institution}

New York Botanical Garden, LuEsther T. Mertz Library

\section{Sponsored by}

BHL-SIL-FEDLINK

\section{Copyright \& Reuse}

Copyright Status: Public domain. The BHL considers that this work is no longer under copyright protection.

This document was created from content at the Biodiversity Heritage Library, the world's largest open access digital library for biodiversity literature and archives. Visit BHL at https://www.biodiversitylibrary.org. 